\title{
Ankle arthrodesis as a salvage procedure: A case of secondary ankle arthritis using Charnley's compression device
}

\author{
by Narayana B.S. Gowda, D Ortho, DNB Ortho, MNAMS ${ }^{1 凶}$, Mohan J. Kumar, MS Ortho ${ }^{2}{ }^{\square}$
}

The Foot and Ankle Online Journal 5 (2): 1

Ankle arthrodesis is commonly considered to be the standard operative treatment for end stage ankle arthritis. The purpose of this study was to perform a clinical and radiographic review to determine functional outcome for a group of patients in whom an ankle arthrodesis had been performed using Charnley's compression device. A functional assessment of fifteen patients after ankle arthrodesis for post traumatic arthritis was carried out by means of an extensive clinical evaluation after an average follow up of 2 years and 8 months.

Key words: Ankle arthrodesis, ankle arthritis, Charnley’s compression device, secondary arthritis ankle.

Accepted: January, $2012 \quad$ Published: February, 2012

This is an Open Access article distributed under the terms of the Creative Commons Attribution License. It permits unrestricted use, distribution, and reproduction in any medium, provided the original work is properly cited. @The Foot and Ankle Online Journal (www.faoj.org), 2011 All rights reserved.

A

nkle arthrodesis is considered by many to be the standard operative treatment for end stage ankle arthritis. ${ }^{1}$ A patient with ankle arthritis and deformity can experience severe pain and functional disability. Treatment options include the use of walking aids, orthotic devices, intra-articular steroids, open rather than arthroscopic debridement, periarticular osteotomy, and arthroplasty, all of which have provided inconsistent relief. Ankle arthrodesis has been accepted by many as yielding good long term clinical results. ${ }^{2}$

Address correspondence to: Asst Professor, Dept of Orthopaedics, PES Medical College, Kuppam, Chittore dist, Andra Pradesh, India, 517425. Email: drnarayan999@yahoo.com, Mob: 00917702990696

\footnotetext{
${ }^{1}$ Asst. Professor, Dept. of Orthopaedics, PES Medical College, Kuppam, Chittore dist., Andra Pradesh, India, 517425.

${ }^{2}$ Asst. Professor, Dept. of Orthopaedics, PES Medical College, Kuppam,

Chittore dist., Andra Pradesh, India, 517425.
}

Although ankle arthroplasty has been used to treat such patients, variable results have been reported and the traditional operative treatment for ankle osteoarthritis has been tibiotalar arthrodesis. ${ }^{3-5}$

Since all the ankle motion is lost after this procedure, some investigators have turned to total ankle replacement, but joint replacement is not always successful even in more favorable joints. Those patients who do not respond to non operative treatment modalities are candidates for ankle arthrodesis, provided pathologic changes in the subtalar region can be ruled out. ${ }^{6}$ Many reports have suggested that ankle arthrodesis reliably provides a painless, plantigrade, stable foot. ${ }^{7}$ 


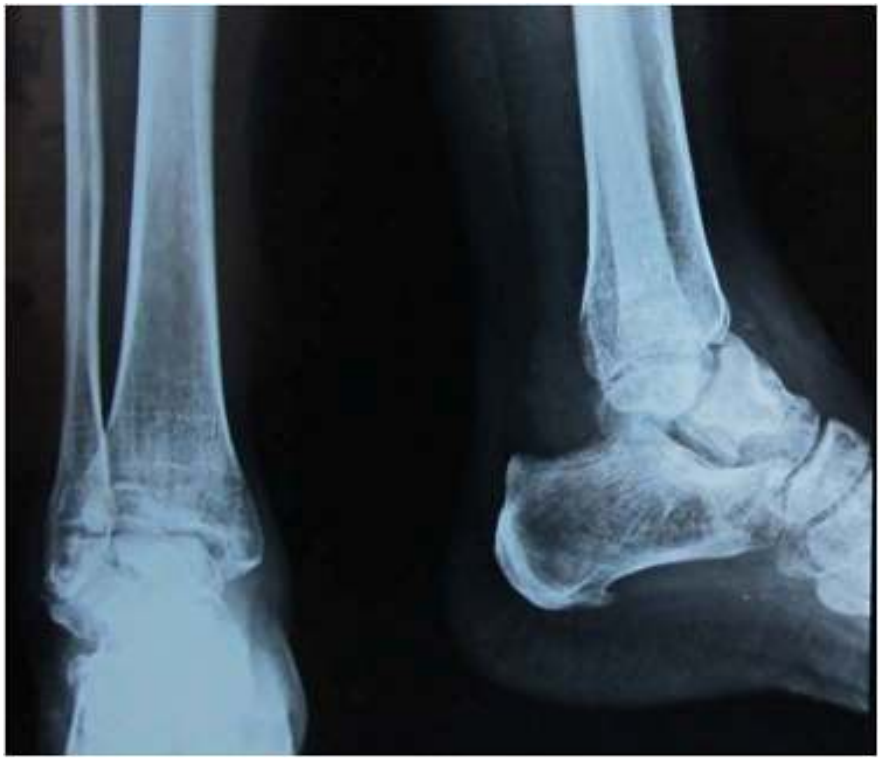

Figure 1 Preoperative radiograph right ankle showing arthritic changes secondary to non union talar neck fracture.

Since 1879, when Albert first described arthrodesis of the ankle ${ }^{8}$, more than thirty different techniques have been described. The open technique with compression and internal fixation is still widely used for ankle arthrodesis with major deformity.9 Ankle arthrodesis is an alternative for cases with intact subtalar joint. ${ }^{10}$ This study presents intermediate term follow up functional outcome of patients with ankle arthrodesis performed using Charnley's compression device.

\section{Materials and methods}

We reviewed fifteen patients, 10 males and 5 females, who had undergone ankle arthrodesis between January 2006 to December 2009 at the People's Education Society (PES) Medical College and Research Center, Kuppam, Andhra Pradesh (AP), India (6 cases of post traumatic AVN talus (Fig. 1), 4 cases malunited bimalleolar fracture, 3 cases of distal tibial plafond fractures, 2 cases of medial malleoli non-union). All the fifteen patients who had secondary ankle arthritis have undergone open ankle fusion with anterolateral approach (Fig. 2) in supine position under tourniquet control and spinal anaesthesia.

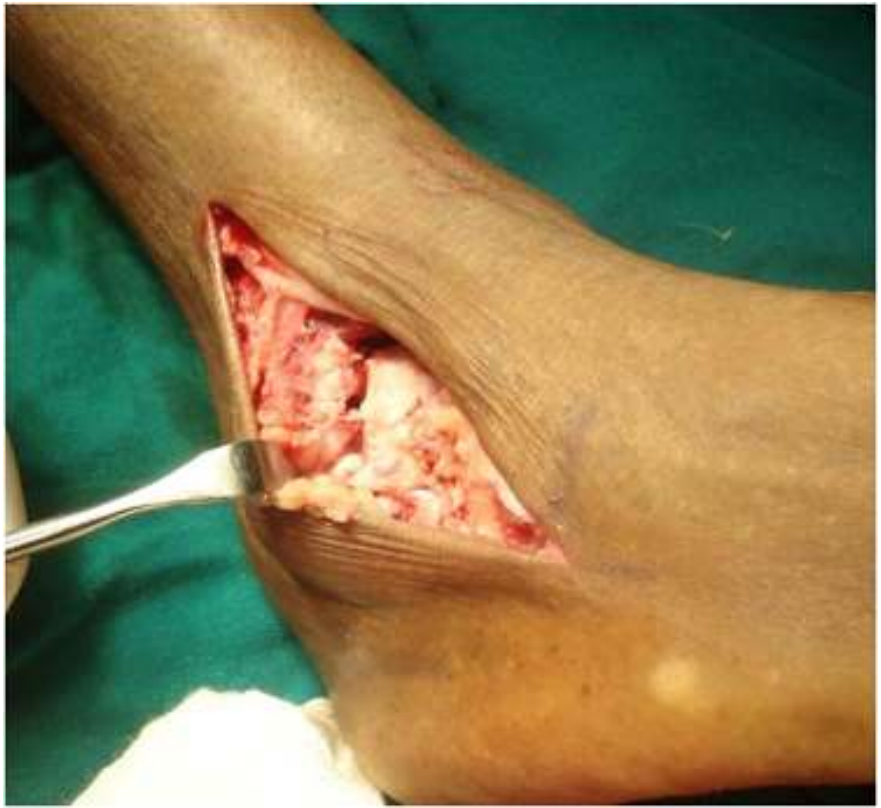

Figure 2 Intraoperative photo showing anterolateral approach to ankle.

Compression was achieved using Charnley's compression device and a calcaneotibial Steinman pin was applied to maintain the alignment and to increase the stability of fixation (Figs. 3 and 4). Suction drain was removed after 48 hours and the patient was made ambulant with non weight on operated site. All the patients were evaluated clinically and radiologically at 6 weeks and tibiocalcaneal Steinman pin was removed and the patients were allowed to bear weight as tolerated. All the fixators were removed after 12 weeks once the arthrodesis site was united radiologically. We had 3 cases of cellulitis of ankle and foot which was treated successfully with antibiotics, and 5 cases of superficial pin tract infection which were healed completely after fixator removal. None of these pin tract infections caused osteomyelitis. The mean age at the time of surgery was 40.52 years (24 56 years) and the time interval between the date of fusion and date of follow up examination ranged from 1 year to 5 years and 7 months, the average being 2 years 8 months. 


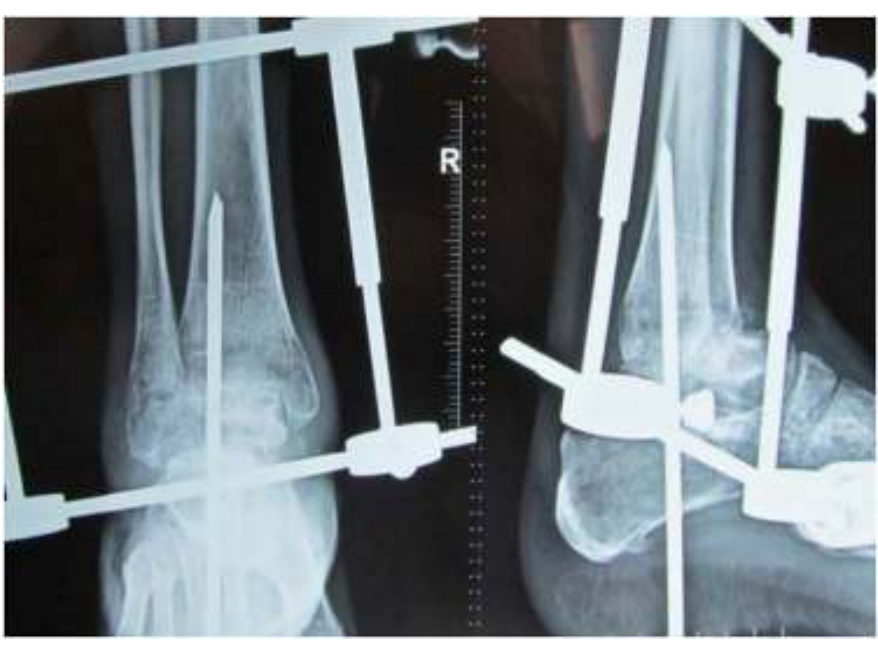

Figure 3 Immediate post operative radiograph showing Charnley's compression device.

\section{Clinical Evaluation}

The clinical evaluation was based on a personal interview and physical examination. The patients were questioned as to their pain during daily activities such as running or walking on the level ground and going up and down the hills and stairs. A complete orthopaedic examination evaluated stance, gait, limb length discrepancy, circumference, range of motion of the knees, ankles, and subtalar joints; neurovascular status muscle strength and presence or absence of tenderness and swelling. Special attention was directed to the position of the fused ankle and the motion of the subtalar and mid tarsal joints. Any valgus or varus deformities of the heel and the presence of the callosities were also determined. The contralateral extremity was used as a control. Ankle anterior posterior and lateral radiographs were taken to assess the fusion and position of the arthrodesis (Fig. 5).

To quantitate the results of the clinical examination the American Orthopaedic Foot and Ankle Society (AOFAS) Ankle-Hindfoot scale was used. The main emphasis of this system was on pain and the functional activities. A normal person would score 100 points. Because of lack of ankle motion, the maximum score that the patient with an ankle fusion could have was 92, since they could not earn the 8 points given for the full range of motion.

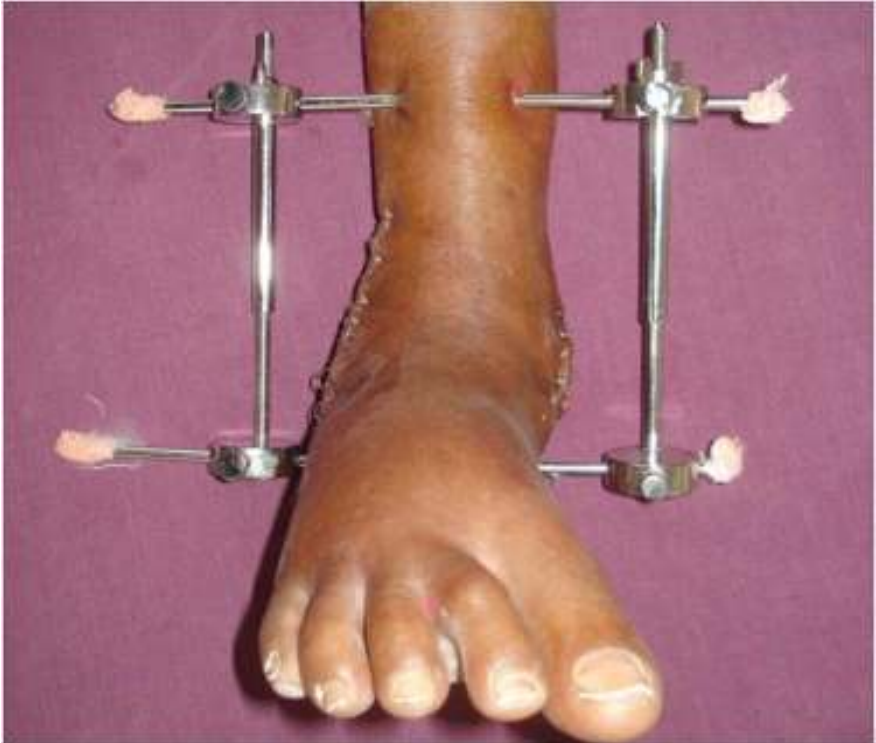

Figure 4 Clinical photo showing Charnley's compression device.

A score of 80 to 92 was considered an excellent result: 70 to 79 , a good result; 60 to 69 , a fair result; and score less than 60 was considered a poor result.

\section{Results}

All patients studied had a solidly fused ankle and had no complications related to the surgery (Fig 6). They were all improved as a result of ankle fusion and returned to their pre injury activities. Wearing shoes with appropriate heels, all the patients could walk on level ground without support. All the patients stated that they could walk up and down the stairs without much difficulty. Limb length discrepancies were insignificant $(0.5$ to $1.5 \mathrm{~cm})$ except in one patient who had $2.5 \mathrm{~cm}$ secondarily due to distal tibial plafond fracture. The radiographs showed that 6 cases showed some evidence of degenerative changes in the subtalar joints which did not correlate with the symptoms.

Scoring the patients with the American Orthopaedic Foot and Ankle Society (AOFAS) Ankle-Hindfoot scale, we found that eleven of the 15 had excellent results; two good; and two fair results. All of them could walk with relatively good velocity and with a consistently rhythmic gait. 


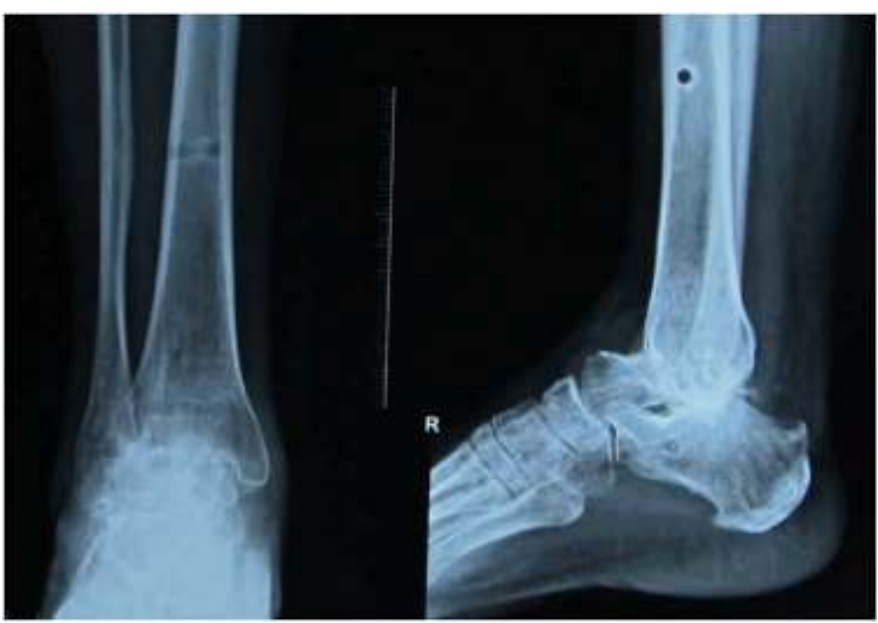

Figure 5 Two year follow up radiographs shows solid union at the arthrodesis site.

\section{Discussion}

The patients with solid ankle fusion in this study functioned very well during the activities of normal daily living. All of them could walk on the level ground without pain. The fusion had permitted them to return to their former occupations and recreational activities. On this basis all the patients could be classified as having very satisfactory results.

Based on the American Orthopaedic Foot and Ankle Society (AOFAS) Ankle-Hindfoot scale, these patients had appreciable limitations when walking barefoot but only mild to moderate limitations when wearing proper footwear. Patients were assessed not only under normal conditions but also under stressful conditions such as walking long distances, climbing up and down the stairs, and running. Six of the 15 could not run. Three had some minor discomfort after walking long distance.

When good surgical technique is used in carefully selected patients, ankle arthrodesis can be a reliable procedure for the relief of functionally disabling ankle arthritis, deformity, and pain ${ }^{9}$ As a fused ankle provides a painless ankle joint with limited functional disability, ankle arthrodesis is still the treatment of choice for most disabling ankle arthritis. ${ }^{10}$

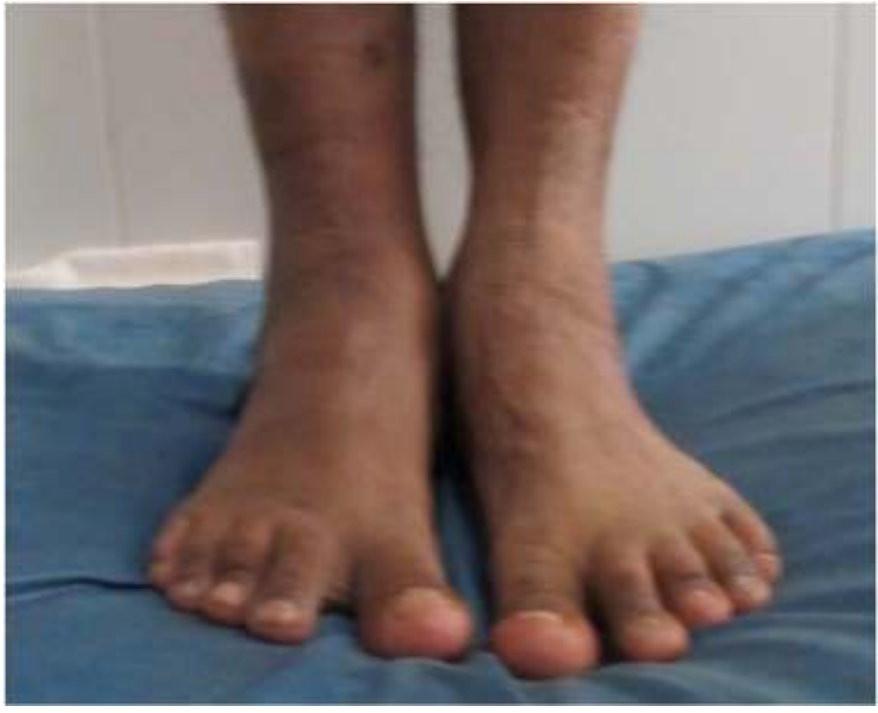

Figure 6 Two year follow up clinical photo of right ankle arthrodesis showing very little difference compared to left normal side.

Charnley's compression devise is still a simple, cost effective and excellent external fixator which can be used easily by every orthopaedic surgeon. After removal of the fixator, there is no indication for additional surgery to remove the implant compared to internal fixation. There are no hardware problems as all the hardware was removed. The high level of satisfaction in this group of patients reinforces the view that open arthrodesis using Charnley's compression device, as opposed to ankle replacement or arthroscopic arthrodesis, continues to be the treatment of choice when there is severe varus or valgus deformity associated with the arthritis. ${ }^{11}$ Although ankle arthrodesis may provide good early relief of pain, it is associated with premature deterioration of other joints of the foot and eventual arthritis, pain, and dysfunction. ${ }^{12-13}$ In studies ranging in size from 12 to 101 patients, rates of successful primary ankle fusion of $80 \%$ to $100 \%$ have been reported earlier. ${ }^{14-18}$ However an average follow up time of 2 years and 8 months is relatively short to comment on the future secondary osteoarthritic changes in the subtalar and mid foot joints. 
To be considered as an alternative preferable to arthrodesis, a total ankle replacement should give better results than those presented here, without other disadvantages. Patients with rheumatoid arthritis and involvement of ankle may not meet the criteria for an ankle arthrodesis may be because they have involvement not only of the ankle but also of the small joints of the foot, so that these joints cannot compensate for the fused ankle. Therefore, patients with rheumatoid arthritis may be better candidates for the total ankle replacement. ${ }^{19}$

\section{Conclusion}

Subjectively and objectively, the patients with ankle fusion function quite well in activities of daily living provided that, they have enough compensatory motion in the Chopart's and Lisfranc joints of the foot, the other ankle has a normal range of motion, they wear footwear with appropriate height. On the basis of these results, patients should be counseled that an ankle fusion will help to relieve pain and to improve overall function; however, it is a salvage procedure that will cause persistent alterations in gait with a potential for deterioration due to the development of ipsilateral hindfoot arthritis. Charnley's compression device can still be considered as the fixator of choice compared to other modalities available with respect to cost, simplicity and good outcome.

\section{References}

1. Coester LM, Saltzman CL, Leupold J, Pontarelli W. Longterm results following ankle arthrodesis for post-traumatic arthritis. JBJS 2001 83A: 219-28. [PubMed]

2. Mazur JM, Schwartz E, Simon SR Ankle arthrodesis, long term follow up with gait analysis. JBJS 1979 61A: 964-975. [PubMed]

3. Helm R, Stevens J. Long-term results of total ankle replacement. J Arthroplasty 1986 1: 271-277. [PubMed]

4. Kofoed H, Lundberg-Jensen A. Ankle arthroplasty in patients younger and older than 50 years: a prospective series with long-term follow-up. Foot Ankle Int 1999 20: 501-506. PubMed]

5. Saltzman CL. Total ankle arthroplasty: state of the art. Instr Course Lect1999 48: 263-268. [PubMed]

6. Huang PJ, Fu YC, Lu CC, Wu WL, Cheng YM. Hindfoot arthrodesis for neuropathic deformity. Kaohsiung J Med Sci 2007 23: 120-127. [PubMed]

7. Mazur JM, Schwartz E, Simon SR. Ankle arthrodesis: Longterm follow-up with gait analysis. JBJS 1979 61A: 964-975. [PubMed]

8. Albert E. Zur Resektion des Kniegelenkes. Wien Med. Press, 1879 20: 705-708.

9. Abidi NA, Gruen GS, Conti SF. Ankle arthrodesis: indications and techniques. Am Acad Orthop Surg 2000 8: 200209. PubMed]

10. Cheng YM, Lin SY, Tien YC, Wu HS. Ankle arthrodesis. Kao Hsiung I Hsueh Ko Hsueh Tsi Chih 1993 9: 524-531. [PubMed]

11. Smith R, Wood PLR. Arthrodesis of the ankle in the presence of a large deformity in the coronal plane. JBJS 2007 89B: 615-619. [ذBJS, full article]

12. Ahlberg A, Henricson AS. Late results of ankle fusion. Acta Orthop Scand 1981 52: 103-105. [PubMed]

13. Boobbyer GN. The long-term results of ankle arthrodesis. Acta Orthop Scand 1981 52: 107-110. [PubMed]

14. Ahlberg A, Henricson AS. Late results of ankle fusion. Acta Orthop Scand 1981 52: 103-105. [PubMed]

15. Bishop AT, Wood MB, Sheetz KK. Arthrodesis of the ankle with a free vascularized autogenous bone graft: Reconstruction of segmental loss of bone secondary to osteomyelitis, tumor, or trauma. JBJS 1995 77A: 1867-1875. PubMed

16. Boobbyer GN. The long-term results of ankle arthrodesis. Acta Orthop Scand 1981 52: 107-110. PubMed]

17. Buck P, Morrey BF, Chao EYS. The optimum position of arthrodesis of the ankle: A gait study of the knee and ankle. JBJS 1987 69A: 1052-1062. PubMed]

18. Lynch AF, Bourne RB, Rorabeck $\mathrm{CH}$. The long-term results of ankle arthrodesis. JBJS 1988 70B: 113-116. [PubMed]

19. Hopgood P, Kumar R, Wood PLR. Ankle arthrodesis for failed total ankle replacement. JBJS 2006 88B: 1032-1038. [PubMed] 